\title{
Associations of dietary macronutrient and fibre intake with glycaemia in individuals with Type 1 diabetes
}

\section{Finnish Diabet Nephropathy Study}

2019-11

Finnish Diabet Nephropathy Study, Ahola , A J , Harjutsalo , V , Forsblom , C , Saraheimo, M \& Groop , P -H 2019 , ' Associations of dietary macronutrient and fibre intake with glycaemia in individuals with Type 1 diabetes ' , Diabetic Medicine , vol. 36 , no. 11 , pp. 1391-1398 . https://doi.org/10.1111/dme.13863

http://hdl.handle.net/10138/321424

https://doi.org/10.1111/dme.13863

unspecified

acceptedVersion

Downloaded from Helda, University of Helsinki institutional repository.

This is an electronic reprint of the original article.

This reprint may differ from the original in pagination and typographic detail.

Please cite the original version. 
Dietary macronutrient and fibre intake and glycaemia in individuals with type 1 diabetes

Running title: Diet and glycaemia in type 1 diabetes

Aila J Ahola ${ }^{1,2,3}$, Valma Harjutsalo ${ }^{1,2,3,4}$, Carol Forsblom ${ }^{1,2,3}$, Markku Saraheimo ${ }^{1,2,3}$, and PerHenrik Groop ${ }^{1,2,3,5 *}$, on behalf of the Finnish Diabetic Nephropathy Study

${ }^{1}$ Folkhälsan Institute of Genetics, Folkhälsan Research Center, Helsinki, Finland

${ }^{2}$ Abdominal Center Nephrology, University of Helsinki and Helsinki University Central Hospital, Helsinki, Finland

${ }^{3}$ Research Programs Unit, Diabetes and Obesity, University of Helsinki, Finland

${ }^{4}$ National Institute for Health and Welfare, Chronic Disease Prevention Unit, Helsinki, Finland

${ }^{5}$ Department of Diabetes, Central Clinical School, Monash University, Melbourne, Victoria, Australia.

*Corresponding author: Per-Henrik Groop, Folkhälsan Research Center, Biomedicum Helsinki C318b, PO Box 63, Fl-00014 University of Helsinki, Finland. Tel +358 2941 25459. Email: perhenrik.groop@helsinki.fi 


\section{Conflicts of interest disclosures}

Professor Per-Henrik Groop has received research grants from Eli Lilly and Roche, is an advisory board member for AbbVie, Astra Zeneca, Boehringer-Ingelheim, Cebix, Eli Lilly, Janssen, MSD, Medscape, Novartis, Novo Nordisk, and Sanofi. He has received lecture fees from Astra Zeneca, Boehringer-Ingelheim, Eli Lilly, Elo Water, Genzyme, MSD, Novartis, Novo Nordisk, and Sanofi. All other authors declare no conflict of interest.

\section{Novelty statement}

- Data on the association between dietary intake and glycaemia, in type 1 diabetes, are mixed and fibre intake is not always accounted for, in the analyses.

- This is a large study among well-defined individuals with type 1 diabetes

- Reported fibre intake was associated with lower mean blood glucose measurements

- Reported protein intake, over any other macronutrients, was associated with lower glucose variability

\section{Acknowledgements}

This work was supported by grants from the Academy of Finland; Novo Nordisk Foundation; Signe and Ane Gyllenberg Foundation; Folkhälsan Research Foundation; Helsinki University Central Hospital Research Funds; Wilhelm and Else Stockmann Foundation; Diabetes Wellness Finland; and Liv och Hälsa Society. Funding agencies played no role in defining the study design, the data collection, the analysis and interpretation of the data, in the writing of the manuscripts, or in the decision to submit the manuscript for publication. The skilled technical assistance of Anna Sandelin, Jaana Tuomikangas, and Mira Korolainen is gratefully acknowledged. Finally, the authors would like to acknowledge all the physicians and nurses participating in the data collection (online appendix). 


\section{Abstract}

Aims To study the association between dietary intake and glycaemia in type 1 diabetes.

Methods Data on energy and nutrient intakes, and mean and coefficient of variation of the self-monitored blood glucose (SMBG) measurements were obtained from records completed by 1000 adults. Associations between these measures of glycaemia and dietary intake were investigated using generalised linear regression with and without macronutrient substitution.

Results In the first set of analyses, fibre intake was associated with lower mean SMBG values $(\mathrm{B}=-0.428,95 \% \mathrm{Cl}=-0.624$ to $-0.231, P<0.001)$. In these same analyses, carbohydrate $(\mathrm{B}=0.011$, 95\% $\mathrm{Cl}=0.002$ to $0.020, P=0.014)$, alcohol $(\mathrm{B}=0.013,95 \% \mathrm{Cl}=0.003$ to $0.023, P=0.009)$, and monounsaturated fatty acid $(B=0.012,95 \% \mathrm{Cl}=0.001$ to $0.023, P=0.029)$ intakes were associated with higher variability in BG measurements. In the macronutrient substitution analyses, substituting proteins for either carbohydrates $(B=-0.026,95 \% \mathrm{Cl}=-0.040$ to -0.013 , $P<0.001)$, fats $(B=-0.018,95 \% \mathrm{Cl}=-0.033$ to $-0.004, P=0.014)$, or alcohol $(\mathrm{B}=-0.026,95 \% \mathrm{Cl}=-$ 0.045 to $-0.006, P=0.010)$, or fats for carbohydrates $(B=-0.009,95 \% \mathrm{Cl}=-0.017$ to -0.001 , $P=0.030$ ) were all associated with lower variability in the measured BG values. After adjusting for fibre intake, no significant results were observed in analyses of mean SMBG.

Conclusions This observational, cross-sectional study indicates that dietary fibre is associated with lower mean blood glucose concentrations in people with type 1 diabetes. Glycaemic excursions were reduced when protein was substituted for other macronutrients and when fat replaced carbohydrate, after adjusting for fibre intake.

Key words: Dietary intake; Fibre; Glycaemia; Macronutrients; Type 1 diabetes 


\section{Introduction}

The role of glycaemic control in the prevention of diabetic complications was first illustrated by the Diabetes Control and Complications Trial (DCCT) [1], and people with type 1 diabetes are now recommended to achieve target $\mathrm{HbA}_{1 \mathrm{c}}$ levels of $<53 \mathrm{mmol} / \mathrm{mol}(<7.0 \%)$ in order to reduce risk [2]. However, as frequently seen, not many individuals with type 1 diabetes achieve these recommendations. For example in two large cohorts of individuals with type 1 diabetes average concentrations at around $67 \mathrm{mmol} / \mathrm{mol}(8.3 \%)$ were reported $[3,4]$. While $\mathrm{HbA}_{1 \mathrm{c}}$ represents long-term glycaemic control, and is therefore the primary indicator of diabetes control, levels of day-to-day glycemia and glycaemic variability contribute to this measure [5]. Moreover, in insulin-treated individuals, high glucose variability may increase the risk of severe hypoglycaemia [6].

Dietary intake plays an important role in the glycaemic control of people with type 1 diabetes. Current evidence in this field is, however, somewhat mixed. For example, analyses are frequently not adjusted for fibre intake [7-10]. Moreover, under isoenergetic conditions, increase in the intake of one macronutrient is accompanied by decrease in the intake of another macronutrient(s). Most of the published studies have not taken such macronutrient substitution into consideration [7, 9-13].

In the current study, we explored the association between dietary intake and glycamia in individuals with type 1 diabetes. In specific, we focused on the macronutrient and fibre intake, and their role in defining mean daily blood glucose values and the variability in these measurements.

\section{Participants and Methods}

Of the participants of the Finnish Diabetic Nephropathy (FinnDiane) Study, we included all with completed food record within 2 years from the study visit and with plausible reported energy intake (5.0-14.6 MJ/d). Individuals with end-stage renal disease were excluded. Type 1 diabetes was defined as onset of diabetes before the age of 35 years, permanent insulin treatment initiated within one year from the diagnosis, and C-peptide negativity. The study protocol was approved by the Ethics Committee of the Helsinki and Uusimaa Hospital District, 
and by the local ethics committees at each centre. Written informed consent was obtained from the participants prior to the study participation.

At the FinnDiane Study visit participants' height and weight were measured in light clothing. Blood pressure was measured twice after a minimum of 10-minutes rest. Mean of the two blood pressure measurements was used in the analyses. Blood was drawn for subsequent central analyses of lipids and lipoproteins. $\mathrm{HbA}_{1 \mathrm{c}}$ was locally measured using standardized assays. Data on diabetic complications, including dialysis and renal transplantation (i.e. endstage renal disease), were collected from medical records. Smoking was self-reported in a questionnaire, and current smoking refers to smoking at least one cigarette per day.

Dietary intake was measured using two separate questionnaires. First participants completed a validated [14] diet questionnaire, and after returning it, a 3-day food record (allocated two consecutive week-days and one week-end day) twice with a 2 to 3-month interval. Detailed instructions with a completed example page were provided. In brief, participants were instructed to report all food-items eaten or drunk during the record-keeping days. Continuation of habitual dietary practices was emphasised. Meticulous reporting of fooditems (e.g. fat contents of liquid milk products, types of fats used for cooking and as spreads, and types of grains in breads) and cooking methods (e.g. boiled, grilled, fried) was encouraged. Brand names of ready-made meals, and recipes for atypical dishes were requested. Instructions were given to report the amounts in common household measures (e.g. spoons, decilitres, and glasses), pieces, centimeters, or grams. Along with reporting their food and beverage intakes in this record, participants also reported physical activity, insulin dosing, and self-monitored blood glucose (SMBG) values. In the current study, only data collected with the records were used. Included were data from participants who had completed at least one 3-day record. From the record entries, average (based on either 3 or 6 days' reported intake) daily energy, nutrient, and fibre (using the Association of Official Analytical Chemists method) intakes were calculated using the AivoDiet software (version 2.0.2.3, AIVO, Turku, Finland), which is based on the Finnish National Food Composition Database. The proportion of energy derived from trans-fatty acids was calculated by subtracting energy derived from saturated fatty acids, monounsaturated fatty acids, and polyunsaturated fatty acids from the total fat intake. Calculated trans-fatty acid intake was used as confounding factor in the analyses. The number of daily blood glucose measurements, 
and mean and coefficient of variation (CV) of the reported SMBG concentrations were calculated for each participant. The calculated SMBG means and CVs were used as continuous variables in the analyses.

Statistical analyses were performed using IBM SPSS Statistics for Windows, Version 22.0 (IBM Corp, Armonk, NY, USA). A two-tailed $P$ value $<0.05$ was considered statistically significant. Categorical variables are presented as frequencies (\%), parametric data are presented as mean $\pm S D$, and non-parametric data are presented as median (interquartile range). Spearman's correlation coefficient was calculated to study the unadjusted correlations between variables. The independent associations between dietary intake and the continuous mean SMBG concentrations and CVs were analysed with generalized linear regression. In the analyses, adjustments were made for age, sex, BMI, triglyceride concentration, insulin dose/kg, physical activity, fibre intake, and other macronutrients. Analyses were conducted with and without macronutrient substitution. In each of the macronutrient substitution models, we included all but one of the macronutrients (per $5 \mathrm{E} \%$ ), total energy intake, and the above-mentioned cofactors. The emerging beta value may be interpreted as increase (when positive) or decrease (when negative) in the given outcome variable when $5 \mathrm{E} \%$ of the excluded macronutrient is substituted with $5 \mathrm{E} \%$ of the macronutrient in question. For example, in an equation: Mean SMBG concentration $=\beta_{0}+\beta_{1}(5 \mathrm{E} \%$ from carbohydrates $)+\beta_{2}$ ( $5 \mathrm{E} \%$ from proteins $)+\beta_{3}(5 \mathrm{E} \%$ from alcohol $)+\beta_{4}(\mathrm{kcal}), \beta_{1}$ would be interpreted as the change in the mean SMBG concentration when dietary carbohydrate intake is increased by $5 \mathrm{E} \%$ at the expense of fats.

\section{Results}

Data on mean SMBG concentration were available from a total of 1000 individuals ( $42 \%$ men, median age 47 years), and the CV of the reported BG concentrations was calculated for 992 participants. Mean SMBG concentration correlated positively with insulin dose, use of insulin pump, body mass index (BMI), triglyceride concentration, and $\mathrm{HbA}_{1 \mathrm{c}}$ (Table 1). Instead, a negative correlation between the mean SMBG concentration and male sex, physical activity, age, and systolic blood pressure was observed. The number of BG measurements, insulin dose, and HDL-cholesterol concentration were positively correlated with the variability of the 
SMBG concentrations, while a negative correlation was observed between the CV and age, systolic blood pressure, diastolic blood pressure, BMI, and triglyceride concentration.

Dietary intake of the population is shown in Table 2. Total fat, saturated fatty acid, and monounsaturated fatty acid intakes were positively associated with mean SMBG concentration. In contrast, carbohydrate, fibre, polyunsaturated fatty acid, and protein intakes were negatively associated with the mean SMBG concentrations. Positive correlations were observed between variability of the BG concentrations and total energy, carbohydrate, sucrose, fat, and alcohol intakes, while the intakes of polyunsaturated fatty acids, and proteins were negatively correlated with the measures of BG variability.

In generalised linear regression analysis where macronutrient substitution was not taken into consideration, fibre intake was negatively associated with mean SMBG concentration (Table 3). Instead, carbohydrate, alcohol, and monounsaturated fatty acid intakes were positively associated with the variability of the BG measurements.

We then investigated the association between macronutrient intake and the two continuous variables of blood glucose monitoring while taking macronutrient substitution into consideration (Table 4). Adjusted for age, sex, BMI, triglyceride concentration, insulin dose/kg, and physical activity, higher mean SMBG concentrations were observed when energy intake from fats was increased at the expense of proteins. Similarly, increased consumption of saturated fatty acids, in place of either monounsaturated or polyunsaturated fatty acids, was associated with higher mean SMBG concentration. After incorporating fibre intake into the model, however, these observations were no longer significant. In the fully adjusted models, favouring either carbohydrates or fats over proteins, was associated with higher variability in the measured BG values. In contrast, lower variability was observed when proteins were substituted for alcohol. Moreover, substituting carbohydrates for fats was associated with higher BG variability.

\section{Discussion}

Current obesrvations highlight the important role of dietary fibre in the management of glycaemia, in type 1 diabetes. Importantly, fibre intake was the only dietary variable 
associated with lower mean SMBG concentrations. The suggested mechanisms through which dietary fibres are thought to exert their glycaemia-reducing effects include, but may not be restricted to, delayed gastric emptying, reduced accessibility of $\alpha$-amylase to its substrates due to fibre-induced increase in the viscosity of the partly digested food mass, and increasing insulin sensitivity related to short-chain fatty acid production by the gut microbiota [15]. Of interest, the self-reported median fibre intake in the current study fell below the Finnish dietary recommendations ( $3 \mathrm{~g} / \mathrm{MJ})[16]$, suggesting that increase in fibre intake could be beneficial in this population.

A number of previous studies investigating the association between dietary intake and glycaemic control have been published. It should be noted, however, that many of these studies were conducted in children or adolescents, rather than in middle-aged adults, a population mainly represented in the current study. The observations made in such studies may not directly translate to the current population. Taking this into consideration, a number of studies have also made a connection between fibre intake and better glycaemic control. For example, in a cross-sectional study including 252 adolescents with type 1 diabetes, with the highest quartile as a reference, the lowest quartile of fibre intake had 3.6 times the odds of having an $\mathrm{HbA}_{1 \mathrm{c}} \geq 69 \mathrm{mmol} / \mathrm{mol}$ ( $\geq 8.5 \%$ ) [7]. In another cross-sectional study, adolescents with type 1 diabetes with optimal glycaemic control $\left(\mathrm{HbA}_{1 \mathrm{c}} \leq 58 \mathrm{mmol} / \mathrm{mol}\right.$ or $\left.\leq 7.5 \%\right)$ had lower intake of added sugars, higher intake of fibre, and higher intake of fruits and vegetables compared to those with less optimal glycaemic control [17]. Of these dietary variables, however, only fibre remained significant after adjustment for potential confounders. A 24week intervention with high-fibre diet (50 g/day), compared to low-fibre diet (15 g/day), significantly reduced mean daily blood glucose concentrations and the number of hypoglycaemic events [18]. In the 7-year prospective analyses of the EURODIAB study, baseline fibre intake below the median (<18 g/day) was associated with higher $\mathrm{HbA}_{1 \mathrm{c}}$ [4]. In addition to studies confirming the beneficial role of fibre, a number of studies were identified where no association between dietary fibre and glycaemia were observed. Amongst these was the prospective SEARCH Nutrition Ancillary Study [19], and a small intervention in children with type 1 diabetes, where addition of fibre into the habitual meal plan did not affect the mean blood glucose excursions after the meals, or the incidence of hypoglycaemia [20]. 
When we investigated the role of macronutrient substitutions for the mean blood glucose concentrations, inclusion of fibre abolished all significant associations observed in the previous models. However, in the analyses dealing with the variability of the measurements, a number of significant observations remained even after controlling for fibre intake. Indeed, substituting proteins for either carbohydrates, fats, or alcohol, as well as substituting fats for carbohydrates were all associated with more stable blood glucose measurements. The role of macronutrient substitutions in the glycaemic control of people with type 1 diabetes was also investigated in the prospective DCCT [8]. In their analyses no macronutrient was significantly associated with the level of glycaemia. Importantly, albeit non-significant observations, these analyses were not adjusted for fibre intake which, as seen in the current study, could play a major role in modifying glycaemia. Moreover, as energy derived from alcohol was also omitted from their analyses, the results have to be interpreted as the effect of substituting the index macronutrient for a combination of alcohol and the other excluded macronutrient.

While beyond the DCCT we are not aware of other reports of macronutrient substitutions and glycaemic control in people with type 1 diabetes, the role of macronutrients in modifying glycaemia has been investigated in various other settings. Dietary carbohydrates in particular, potentially due to their pronounced connection with the blood glucose concentrations, have gained substantial interest. The current evidence of the role of carbohydrates for the glycaemic control is, however, somewhat mixed. Over an 18-month behavioural nutrition intervention trial among 136 adolescents with type 1 diabetes, higher intake of carbohydrates was associated with lower $\mathrm{HbA}_{1 c}$ [9]. In contrast, in a cross-sectional study of 46,010 children and adolescents with type 1 diabetes, lower carbohydrate intake was associated with lower $\mathrm{HbA}_{1 \mathrm{c}}[10]$. To our knowledge, however, neither of these two analyses were corrected for other dietary variables such as fibre. Yet in another cross-sectional study, accounting for fibre intake, higher carbohydrate intake was positively associated with time spent in euglycaemia, and negatively with time spent in hyperglycaemia [11]. Furthermore, even when adjusted for fibre intake, the source of carbohydrates may be important, as was seen in cross-sectional analyses of the EURODIAB study where higher intakes of total carbohydrates and potatoderived carbohydrates, but lower intakes of vegetable-based carbohydrates, were associated with less optimal $\mathrm{HbA}_{1 \mathrm{c}}$ [12]. It has also been suggested that it is not the total amount of carbohydrates in the diet per se that determines the level of glycaemia, but rather the 
consistency of carbohydrate and starch intake from meal to meal [21]. After all, consistency in the eating behaviours related to carbohydrate containing foods may improve the accuracy of carbohydrate counting. Considering the substantial errors observed in estimating carbohydrate contents of the meals [22] and with considerable intra-individual variability in the metabolic effect of the injected insulin [23], the potential of reduced carbohydrate intake in improving glycaemia has also been investigated. Indeed, in a number of low-carbohydrate diet interventions significant improvements in glycaemic control of individuals with type 1 diabetes have been reported [24, 25]. Moreover, in one short-term low-carbohydrate diet intervention, although mean glucose concentrations were not impacted, lower glucose variability, more time spent in euglycaemia, and less time in hypoglycaemia were observed [26]. However, more studies are needed to reveal the health effects of low-carbohdyrate diets, as there is currently insufficient evidence to support their use in type 1 diabetes [27].

As is the case for carbohydrates, the results obtained for the role of fats in glycaemic control are also mixed. While in three prospective studies baseline intake of total fat was not associated with glycaemic control measured at the end of the follow-up period $[4,8,19]$, a number of cross-sectional studies have associated higher intakes of either total fats or saturated fatty acids with less optimal glycaemic control. Amongst these is a study in 33 adult individuals with type 1 diabetes, where higher fat intakes were correlated with less time in euglycemia, and more time in hyperglycaemia [11]. In another study in 252 adolescents with type 1 diabetes, the highest quartile of fat intake increased the risk of suboptimal glycaemic control 2.5-fold [7]. In children and adolescents with type 1 diabetes, intake of saturated fatty acids was associated with $53 \%$ increased risk of having $\mathrm{HbA}_{1 \mathrm{c}}$ concentrations above the recommended $58 \mathrm{mmol} / \mathrm{mol}$ (7.5\%) [13]. In line with the above study, intake of saturated fatty acids when replacing polyunsaturated fatty acids was also in the current study associated with worse glycaemic control, measured both as higher mean SMBG concentrations and the variability of these measurements. These effects were, however, lost after further adjustment for fibre intake.

In the current analyses, higher intake of protein at the expence of any other macronutrient was associated with lower variability of the measured blood glucose concentrations. We are not aware of other studies reporting similar findings. In contrast, Nansel et al observed that lower protein intake was associated with better glycaemic control [9]. In another study, no 
correlation between protein intake and time spent in hypoglycaemia, euglycaemia, or hyperglycaemia were observed [11]. The longitudinal analyses of the EURODIAB study revealed that, although baseline intakes of total protein did not determine glycaemia, intake of vegetable protein below median ( $<29 \mathrm{~g} /$ day) was associated with worse glycaemic control [4]. In the prospective SEARCH Nutrition Ancillary Study, instead, not only total protein intake but also vegetable and animal protein intakes predicted lower $\mathrm{HbA}_{1 c}$ concentrations at the end of the mean 1.5 years of follow-up [19]. In the current study, the source of protein was not examined.

The mechanisms behind current observations relating protein intake to more stable blood glucose measurements is not known. It is possible, however, that the mechanism is not directly related to protein intake but rather to what they are replacing. Indeed, while carbohydrates are known to directly boost blood glucose concentrations, alcohol intake, via reduction in the hepatic gluconeogenesis, has the potential to reduce blood glucose concentrations over the following 10-12 hours [28]. Dietary fats, on the other hand, due to delayed gastric emptying, reduce early glucose response [29], and via free fatty acid-induced insulin resistance, cause delay in the emergence of the postpradial blood glucose peak [30, 31]. While also proteins are known to increase blood glucose concentrations in the late postprandial period [31], based on the current observations it may be speculated that compared to the other macronutrients, ingestion of proteins leads to less pronounced changes in the blood glucose fluctuations. Moreover, people with type 1 diabetes may be better able to take dietary proteins into account when estimating their prandial insulin dosing. Indeed, although estimating the required prandial insulin dose has traditionally been based on carbohydrate counting, there is increasing evidence that also fats and proteins may need to be taken into consideration. To this end, calculating the so-called fat-protein units has recently been introduced as a method to estimate the required bolus insulin to cover the glycaemic effects of these macronutrients [32]. In this method, each $100 \mathrm{kcal}$ derived from the combination of ingested fats and proteins are considered to call for the same amount of insulin as 10 grams of carbohydrates. Importantly, the application of this method in a dual wave or square wave bolus mode, has shown to improve glycaemic control in individuals with type 1 diabetes [32, 33]. 
There are strengths and limitations related to the current study. Amongst the limitations is the use of self-reported data for both dietary intake and blood glucose monitoring. There may be a tendency to over-report the consumption of foods regarded as healthy and under-report those considered unhealthy. While it may be difficult to control for such a phenomenon we did, however, try to control for potential under- or over-reporting of total energy intake. Various cut-off values may be used to identify under- and over-reporters. According to Willett, for example, mean daily intakes between 500 and $4000 \mathrm{kcal}$ (2.1 MJ and $16.7 \mathrm{MJ}$ ) may be considered appropriate [34]. Taking into consideration the characteristics of the current study population (type 1 diabetes, average age and BMI) we, however, chose to use more conservative cut-off levels of $5 \mathrm{MJ}$ and $14.6 \mathrm{MJ}$, as intakes closer to $500 \mathrm{kcal}$ and $4000 \mathrm{kcal}$ may not be plausible in the long-term. The self-reported blood glucose measurements are a mixture of pre- and post-prandial values. Variation in the timing of measurements has likely taken place, and may be a source of bias in the current study. Importantly, studies taking advantage of continuous glucose monitoring devices have, amongst others, shown that fibre intake is associated with more optimal glycaemic control [9]. In contrast, the results related to protein intake, in these studies, have been mixed as increased postprandial glucose excursions [31], increased hypoglycaemic events [35], as well as no effect on postprandial, overnight, or late night glucose concentrations [36] have been reported. Furthermore, whether self-reporting of blood glucose measurements were subject to misreporting, in the current study, is not known. Due to issues related to social desirability it is possible that extremely high or low values are less frequently reported. If such misreporting has taken place, it has most likely attenuated the current observations. The participants included in the FinnDiane Study have been carefully assessed regarding their type of diabetes. Key features are onset of diabetes before the age of 35 years, initiation of insulin treatment within a year of the diagnosis, and C-peptide negativity. These features are all typical of type 1 diabetes and we are therefore confident that misclassification is not an issue in this cohort. Finally, the potential for residual confounding cannot be excluded. In particular, smoking and socioeconomic status were not accounted for, in the analyses, as multicollinearity between these variables and a number of variables included in the model were observed. A large population of well-defined individuals is one of the strengths of the current study. Moreover, the cross-sectional study design is suitable for the current study, considering that our aim was to look at the relationship between dietary intake and the concomitant glycaemia. Using the 
record method ensured that the measures of dietary intake did not reflect dietary history, but were the intakes that also covered the period when blood glucose concentrations were monitored.

In conclusion, based on the observations made in this cross-sectional study, dietary fibre plays a major role in the successful management of glycaemia in type 1 diabetes. Moreover, even when adjusted for fibre intake, proteins, when replacing excess carbohydrates, fats, or alcohol, may reduce glycaemic excursions. In the future, long-term effects of dietary intake in the risk of diabetic complications will be investigated.

\section{Funding}

This work was supported by grants from the Academy of Finland; Novo Nordisk Foundation; Signe and Ane Gyllenberg Foundation; Folkhälsan Research Foundation; Helsinki University Central Hospital Research Funds; Wilhelm and Else Stockmann Foundation; Diabetes Wellness Finland; and Liv och Hälsa Society. Funding agencies played no role in defining the study design, in the data collection, analysis and interpretation of data, in the writing of the manuscripts, or in the decision to submit the manuscript for publication.

\section{Conflicts of Interest}

Professor Per-Henrik Groop has received research grants from Eli Lilly and Roche, is an advisory board member for AbbVie, Astra Zeneca, Boehringer-Ingelheim, Cebix, Eli Lilly, Janssen, MSD, Medscape, Novartis, Novo Nordisk, and Sanofi. He has received lecture fees from Astra Zeneca, Boehringer-Ingelheim, Eli Lilly, Elo Water, Genzyme, MSD, Novartis, Novo Nordisk, and Sanofi. All other authors declare no conflict of interest.

\section{Acknowledgements}

We greatfully acknowledge Anna Sandelin, Jaana Tuomikangas, and Mira Korolainen for the skilled technical assistance. Finally, authors acknowledge all the physicians and nurses participating in data collection (online appendix).

\section{References}

1 The Diabetes Control and Complications Trial Research Group. The effect of intensive treatment of diabetes on the development and progression of long-term complications in insulin-dependent diabetes mellitus. N Engl J Med 1993; 329: 977-986. 
2 American Diabetes Association. 6. Glycemic Targets: Standards of Medical Care in Diabetes-2018. Diabetes Care 2018; 41: S55-S64.

3 Ahola AJ, Harjutsalo V, Forsblom C, Groop PH. Renin-angiotensin-aldosterone-blockade is associated with decreased use of antidepressant therapy in patients with type 1 diabetes and diabetic nephropathy. Acta Diabetol 2014; 51: 529-533.

4 Balk SN, Schoenaker DA, Mishra GD, Toeller M, Chaturvedi N, Fuller JH et al. Association of diet and lifestyle with glycated haemoglobin in type 1 diabetes participants in the EURODIAB prospective complications study. Eur J Clin Nutr 2016; 70: 229-236.

5 Sartore G, Chilelli NC, Burlina S, Di Stefano P, Piarulli F, Fedele D et al. The importance of HbA1c and glucose variability in patients with type 1 and type 2 diabetes: outcome of continuous glucose monitoring (CGM). Acta Diabetol 2012; 49 Suppl 1: S153-160.

6 Guelho D, Paiva I, Batista C, Barros L, Carrilho F. A1c, glucose variability and hypoglycemia risk in patients with type 1 diabetes. Minerva Endocrinol 2014; 39: 127-133.

7 Katz ML, Mehta S, Nansel T, Quinn H, Lipsky LM, Laffel LM. Associations of nutrient intake with glycemic control in youth with type 1 diabetes: differences by insulin regimen. Diabetes Technol Ther 2014; 16: 512-518.

8 Delahanty LM, Nathan DM, Lachin JM, Hu FB, Cleary PA, Ziegler GK et al. Association of diet with glycated hemoglobin during intensive treatment of type 1 diabetes in the Diabetes Control and Complications Trial. Am J Clin Nutr 2009; 89: 518-524.

9 Nansel TR, Lipsky LM, Liu A. Greater diet quality is associated with more optimal glycemic control in a longitudinal study of youth with type 1 diabetes. Am J Clin Nutr 2016; 104: 81-87.

10 Meissner T, Wolf J, Kersting M, Fröhlich-Reiterer E, Flechtner-Mors M, Salgin B et al. Carbohydrate intake in relation to $\mathrm{BMI}, \mathrm{HbA1c}$ and lipid profile in children and adolescents with type 1 diabetes. Clin Nutr 2014; 33: 75-78.

11 Ayano-Takahara S, Ikeda K, Fujimoto S, Asai K, Oguri Y, Harashima S et al. Carbohydrate intake is associated with time spent in the euglycemic range in patients with type 1 diabetes. $J$ Diabetes Investig 2015; 6: 678-686.

12 Buyken AE, Toeller M, Heitkamp G, Irsigler K, Holler C, Santeusanio F et al. Carbohydrate sources and glycaemic control in Type 1 diabetes mellitus. EURODIAB IDDM Complications Study Group. Diabet Med 2000; 17: 351-359.

13 Maffeis C, Morandi A, Ventura E, Sabbion A, Contreas G, Tomasselli F et al. Diet, physical, and biochemical characteristics of children and adolescents with type 1 diabetes: relationship between dietary fat and glucose control. Pediatr Diabetes 2012; 13: 137-146.

14 Ahola AJ, Lassenius MI, Forsblom C, Harjutsalo V, Lehto M, Groop PH. Dietary patterns reflecting healthy food choices are associated with lower serum LPS activity. Sci Rep 2017; 7: 6511-017-068857.

15 James SL, Muir JG, Curtis SL, Gibson PR. Dietary fibre: a roughage guide. Intern Med J 2003; 33: 291-296.

16 National Nutrition Council. Finnish dietary recommendations. https://www.evira.fi/globalassets/vrn/pdf/ravitsemussuositukset_terveyttaruoasta_2014_fi_web_v4.pdf. Accessed 21 May 2018. 
17 Overby NC, Margeirsdottir HD, Brunborg C, Andersen LF, Dahl-Jorgensen K. The influence of dietary intake and meal pattern on blood glucose control in children and adolescents using intensive insulin treatment. Diabetologia 2007; 50: 2044-2051.

18 Giacco R, Parillo M, Rivellese AA, Lasorella G, Giacco A, D’Episcopo L et al. Long-term dietary treatment with increased amounts of fiber-rich low-glycemic index natural foods improves blood glucose control and reduces the number of hypoglycemic events in type 1 diabetic patients. Diabetes Care 2000; 23: 1461-1466.

19 Lamichhane AP, Crandell JL, Jaacks LM, Couch SC, Lawrence JM, Mayer-Davis EJ. Longitudinal associations of nutritional factors with glycated hemoglobin in youth with type 1 diabetes: the SEARCH Nutrition Ancillary Study. Am J Clin Nutr 2015; 101: 1278-1285.

20 Nader N, Weaver A, Eckert S, Lteif A. Effects of fiber supplementation on glycemic excursions and incidence of hypoglycemia in children with type 1 diabetes. Int J Pediatr Endocrinol 2014; 13: 10.1186/1687-9856-2014-13.

21 Wolever TM, Hamad S, Chiasson JL, Josse RG, Leiter LA, Rodger NW et al. Day-to-day consistency in amount and source of carbohydrate intake associated with improved blood glucose control in type 1 diabetes. J Am Coll Nutr 1999; 18: 242-247.

22 Brazeau AS, Mircescu H, Desjardins K, Leroux C, Strychar I, Ekoé JM et al. Carbohydrate counting accuracy and blood glucose variability in adults with type 1 diabetes. Diabetes Res Clin Pract 2013; 99: 19-23.

23 Heinemann L. Variability of insulin absorption and insulin action. Diabetes Technol Ther 2002; 4: 673-682.

24 Nielsen JV, Gando C, Joensson E, Paulsson C. Low carbohydrate diet in type 1 diabetes, long-term improvement and adherence: A clinical audit. Diabetol Metab Syndr 2012; 4: 23-5996-4-23.

25 Krebs JD, Parry Strong A, Cresswell P, Reynolds AN, Hanna A, Haeusler S. A randomised trial of the feasibility of a low carbohydrate diet vs standard carbohydrate counting in adults with type 1 diabetes taking body weight into account. Asia Pac J Clin Nutr 2016; 25: 78-84.

26 Ranjan A, Schmidt S, Damm-Frydenberg C, Holst JJ, Madsbad S, Norgaard K. Short-term effects of a low carbohydrate diet on glycaemic variables and cardiovascular risk markers in patients with type 1 diabetes: A randomized open-label crossover trial. Diabetes Obes Metab 2017; 19: 1479-1484.

27 Turton JL, Raab R, Rooney KB. Low-carbohydrate diets for type 1 diabetes mellitus: A systematic review. PLoS One 2018;13:e0194987.

28 Plougmann S, Hejlesen O, Turner B, Kerr D, Cavan D. The effect of alcohol on blood glucose in Type 1 diabetes--metabolic modelling and integration in a decision support system. Int J Med Inform 2003; 70: 337-344.

29 Bell KJ, Smart CE, Steil GM, Brand-Miller JC, King B, Wolpert HA. Impact of fat, protein, and glycemic index on postprandial glucose control in type 1 diabetes: implications for intensive diabetes management in the continuous glucose monitoring era. Diabetes Care 2015; 38: 1008-1015.

30 Roden M, Price TB, Perseghin G, Petersen KF, Rothman DL, Cline GW et al. Mechanism of free fatty acid-induced insulin resistance in humans. J Clin Invest 1996; 97: 2859-2865.

31 Smart CE, Evans M, O'Connell SM, McElduff P, Lopez PE, Jones TW et al. Both dietary protein and fat increase postprandial glucose excursions in children with type 1 diabetes, and the effect is additive. Diabetes Care 2013; 36: 3897-3902. 
32 Pankowska E, Szypowska A, Lipka M, Szpotanska M, Blazik M, Groele L. Application of novel dual wave meal bolus and its impact on glycated hemoglobin A1c level in children with type 1 diabetes. Pediatr Diabetes 2009; 10: 298-303.

33 Herron A, Sullivan C, Brouillard E, Steenkamp D. Late to the Party: Importance of Dietary Fat and Protein in the Intensive Management of Type 1 Diabetes. A Case Report. J Endocr Soc 2017; 1: 10021005.

34 Willet W. Nutritional Epidemiology. $3^{\text {rd }}$ ed. New York, NY: Oxford University Press. 2013.

35 Zhong VW, Crandell JL, Shay CM, Gordon-Larsen P, Cole SR, Juhaeri J et al. Dietary intake and risk of non-severe hypoglycemia in adolescents with type 1 diabetes. J Diabetes Complications 2017; 31: 1340-1347.

36 Borie-Swinburne C, Sola-Gazagens A, Gonfroy-Leymarie C, Boillot J, Boitard C, Larger E. Effect of dietary protein on post-prandial glucose in patients with type 1 diabetes. J Hum Nutr Diet 2013; 26: 606-611. 
Table 1 Basic characteristics of the population, and correlations between the basic characteristics and measures of glycaemia

\begin{tabular}{|c|c|c|c|c|c|}
\hline & \multirow[t]{2}{*}{ Total population } & \multicolumn{2}{|c|}{ Mean SMBG } & \multicolumn{2}{|c|}{ CV of SMBG } \\
\hline & & $r$ & $P$ & $r$ & $P$ \\
\hline Mean SMBG & $8.1(6.8-9.4)$ & & & 0.093 & 0.003 \\
\hline CV of SMBG & $0.42(0.34-0.49)$ & 0.093 & 0.003 & & \\
\hline Measurements/day, $\mathrm{n}$ & $3.8(2.7-5.0)$ & 0.039 & 0.223 & 0.078 & 0.014 \\
\hline Men, $\%$ & 42.4 & -0.084 & 0.008 & -0.061 & 0.056 \\
\hline Insulin dose, IU/kg & $0.56(0.43-0.71)$ & 0.128 & $<0.001$ & 0.079 & 0.013 \\
\hline Insulin pump, \% & 16 & 0.069 & 0.029 & -0.029 & 0.360 \\
\hline Physical activity, METh/d & $19(9-34)$ & -0.134 & $<0.001$ & 0.045 & 0.207 \\
\hline Age, years & $47(37-58)$ & -0.146 & $<0.001$ & -0.091 & 0.004 \\
\hline $\mathrm{SBP}, \mathrm{mmHg}$ & $136(124-149)$ & -0.098 & 0.002 & -0.078 & 0.015 \\
\hline $\mathrm{DBP}, \mathrm{mmHg}$ & $76 \pm 9$ & 0.054 & 0.089 & -0.077 & 0.015 \\
\hline $\mathrm{BMI}, \mathrm{kg} / \mathrm{m}^{2}$ & $25.5(23.2-28.3)$ & 0.106 & 0.001 & -0.073 & 0.022 \\
\hline Total cholesterol, mmol/l & $4.6(4.0-5.1)$ & -0.028 & 0.400 & -0.009 & 0.785 \\
\hline HDL cholesterol, mmol/l & $1.57(1.32-1.90)$ & -0.057 & 0.085 & 0.114 & 0.001 \\
\hline Triglycerides, mmol/l & $0.94(0.71-1.27)$ & 0.140 & $<0.001$ & -0.099 & 0.003 \\
\hline $\mathrm{HbA}_{1 \mathrm{c}}, \mathrm{mmol} / \mathrm{mol}$ & $63(55-71)$ & 0.451 & $<0.001$ & 0.029 & 0.366 \\
\hline $\mathrm{HbA}_{1 \mathrm{c}}, \%$ & $7.9(7.2-8.6)$ & 0.451 & $<0.001$ & 0.029 & 0.366 \\
\hline Current smoker, \% & 10.4 & 0.024 & 0.451 & -0.032 & 0.317 \\
\hline
\end{tabular}

Data are presented as median (interquartile range) for continuous variables that were skewed, mean \pm standard deviation for continuous variables with normal distribution, frequency (\%) for categorical variables, and Spearman's correlation coefficients with respective $P$-values. SMBG, self-monitored blood glucose; CV, coefficient of variation; IU, international unit; METh, metabolic equivalent of task hours; SBP, systolic blood pressure; DBP, diastolic blood pressure; BMI, body mass index. 
Table 2 Reported energy, macronutrient, sucrose, and fibre intakes of the population, and correlations between dietary intake and measures of glycaemia

\begin{tabular}{|c|c|c|c|c|c|}
\hline & \multirow[t]{2}{*}{ Total population } & \multicolumn{2}{|c|}{ Mean SMBG } & \multicolumn{2}{|c|}{ CV of SMBG } \\
\hline & & $r$ & $P$ & $r$ & $P$ \\
\hline Energy, MJ & $7.8(6.6-9.1)$ & -0.015 & 0.629 & 0.123 & $<0.001$ \\
\hline Carbohydrates, g & $196(161-236)$ & -0.045 & 0.152 & 0.157 & $<0.001$ \\
\hline Carbohydrates, E\% & $42.8(38.3-47.1)$ & -0.072 & 0.023 & 0.104 & 0.001 \\
\hline Sucrose, g & $32(21-47)$ & 0.050 & 0.115 & 0.194 & $<0.001$ \\
\hline Fibre, g & $21(17-27)$ & -0.204 & $<0.001$ & 0.027 & 0.402 \\
\hline Fibre, g/MJ & $2.7(2.2-3.4)$ & -0.210 & $<0.001$ & -0.052 & 0.101 \\
\hline Fats, $\mathrm{g}$ & $74(60-91)$ & 0.037 & 0.238 & 0.064 & 0.043 \\
\hline Fats, E\% & $36.2(31.9-40.2)$ & 0.097 & 0.002 & -0.059 & 0.065 \\
\hline SAFA, E\% & $12.7(10.7-14.6)$ & 0.156 & $<0.001$ & 0.002 & 0.954 \\
\hline MUFA, E\% & $12.1(10.6-13.8)$ & 0.064 & 0.043 & -0.053 & 0.093 \\
\hline PUFA, E\% & $5.9(5.1-7.0)$ & -0.082 & 0.009 & -0.080 & 0.012 \\
\hline Proteins, g & $77(65-94)$ & -0.049 & 0.124 & -0.011 & 0.740 \\
\hline Proteins, E\% & $16.6(14.8-18.7)$ & -0.062 & 0.051 & -0.176 & $<0.001$ \\
\hline Proteins, g/kg & $1.05(0.87-1.27)$ & -0.091 & 0.004 & 0.036 & 0.253 \\
\hline Alcohol, E\% & $0.8(0-3.0)$ & -0.021 & 0.515 & 0.083 & 0.009 \\
\hline
\end{tabular}

Data are presented as median (interquartile range), and Spearman correlation coefficient with respective $P$-value. SMBG, self-monitored blood glucose; $C V$, coefficient of variation; SAFA, saturated fatty acids; MUFA, monounsaturated fatty acids; PUFA, polyunsaturated fatty acids. 
Table 3 The association between SMBG and CV and energy-adjusted reported macronutrient and fibre intakes

\begin{tabular}{|c|c|c|c|c|c|c|}
\hline & \multicolumn{3}{|c|}{ Mean SMBG } & \multicolumn{3}{|c|}{ CV of SMBG } \\
\hline & $\mathrm{B}$ & 95\% Wald Confidence Interval & $P$ & $\mathrm{~B}$ & 95\% Wald Confidence Interval & $P$ \\
\hline Carbohydrates, E\% & 0.045 & -0.084 to 0.175 & 0.493 & 0.011 & 0.002 to 0.020 & 0.014 \\
\hline Proteins, E\% & 0.034 & -0.105 to 0.173 & 0.631 & 0.006 & -0.003 to 0.016 & 0.190 \\
\hline Alcohol, E\% & 0.017 & -0.121 to 0.155 & 0.810 & 0.013 & 0.003 to 0.023 & 0.009 \\
\hline SAFA, E\% & 0.069 & -0.072 to 0.210 & 0.338 & 0.009 & -0.001 to 0.019 & 0.081 \\
\hline MUFA, E\% & -0.016 & -0.170 to 0.137 & 0.834 & 0.012 & 0.001 to 0.023 & 0.029 \\
\hline PUFA, E\% & 0.034 & -0.130 to 0.198 & 0.683 & 0.007 & -0.004 to 0.018 & 0.233 \\
\hline Fibre, g/MJ & -0.428 & -0.624 to -0.231 & $<0.001$ & -0.011 & -0.024 to 0.003 & 0.121 \\
\hline
\end{tabular}

SMBG, self-monitored blood glucose; CV, coefficient of variation; $\beta$, regression coefficient; SAFA, saturated fatty acids; MUFA, monounsaturated fatty acids; PUFA, polyunsaturated fatty acids. The model, including all dietary variables, is adjusted for age, sex, BMI, triglyceride concentration, trans fatty acids, insulin dose $/ \mathrm{kg}$, and physical activity. Generalised linear regression. 
Table 4 The association between mean and coefficient of variation of blood glucose measurements and reported macronutrient intake (substitution model)

\begin{tabular}{|c|c|c|c|c|c|c|c|}
\hline \multirow[b]{2}{*}{$\begin{array}{l}\text { Macronutrient intake } \\
\text { increased (decreased) }\end{array}$} & \multicolumn{4}{|c|}{ Mean SMBG } & \multicolumn{3}{|c|}{ CV of SMBG } \\
\hline & Model & B & $\begin{array}{l}\text { 95\% Wald Confidence } \\
\text { Interval }\end{array}$ & $P$ & B & $\begin{array}{l}\text { 95\% Wald Confidence } \\
\text { Interval }\end{array}$ & $P$ \\
\hline \multirow[t]{2}{*}{ Carbohydrate (fat) } & 1 & -0.106 & -0.220 to 0.008 & 0.067 & 0.005 & -0.002 to 0.013 & 0.181 \\
\hline & 2 & -0.007 & -0.123 to 0.109 & 0.911 & 0.009 & 0.001 to 0.017 & 0.030 \\
\hline \multirow[t]{2}{*}{ Carbohydrate (protein) } & 1 & 0.100 & -0.097 to 0.296 & 0.320 & 0.028 & 0.015 to 0.041 & $<0.001$ \\
\hline & 2 & 0.065 & -0.122 to 0.253 & 0.496 & 0.026 & 0.013 to 0.040 & $<0.001$ \\
\hline \multirow[t]{2}{*}{ Carbohydrate (alcohol) } & 1 & 0.026 & -0.187 to 0.239 & 0.810 & -0.006 & -0.021 to 0.008 & 0.410 \\
\hline & 2 & 0.156 & -0.053 to 0.365 & 0.143 & -0.002 & -0.016 to 0.013 & 0.824 \\
\hline \multirow[t]{2}{*}{ Fat (protein) } & 1 & 0.215 & 0.009 to 0.421 & 0.041 & 0.023 & 0.009 to 0.037 & 0.001 \\
\hline & 2 & 0.076 & -0.129 to 0.282 & 0.467 & 0.018 & 0.004 to 0.033 & 0.014 \\
\hline \multirow[t]{2}{*}{ Fat (alcohol) } & 1 & 0.148 & -0.078 to 0.374 & 0.200 & -0.009 & -0.024 to 0.007 & 0.264 \\
\hline & 2 & 0.164 & -0.053 to 0.382 & 0.138 & -0.009 & -0.024 to 0.006 & 0.235 \\
\hline \multirow[t]{2}{*}{ SAFA (MUFA) } & 1 & 0.681 & 0.131 to 1.231 & 0.015 & 0.027 & -0.011 to 0.064 & 0.161 \\
\hline & 2 & 0.387 & -0.162 to 0.936 & 0.167 & 0.015 & -0.024 to 0.054 & 0.445 \\
\hline \multirow[t]{2}{*}{ SAFA (PUFA) } & 1 & 0.717 & 0.331 to 1.103 & $<0.001$ & 0.034 & 0.008 to 0.060 & 0.011 \\
\hline & 2 & 0.229 & -0.207 to 0.665 & 0.303 & 0.022 & -0.009 to 0.052 & 0.166 \\
\hline \multirow[t]{2}{*}{ MUFA (PUFA) } & 1 & 0.372 & -0.319 to 1.062 & 0.291 & 0.058 & 0.011 to 0.105 & 0.015 \\
\hline & 2 & -0.149 & -0.860 to 0.562 & 0.681 & 0.045 & -0.005 to 0.095 & 0.078 \\
\hline \multirow[t]{2}{*}{ Protein (alcohol) } & 1 & -0.022 & -0.307 to 0.263 & 0.880 & -0.031 & -0.050 to -0.011 & 0.002 \\
\hline & 2 & 0.108 & -0.167 to 0.383 & 0.441 & -0.026 & -0.045 to -0.006 & 0.010 \\
\hline
\end{tabular}

SMBG, self-monitored blood glucose; CV, coefficient of variation; SAFA, saturated fatty acids; MUFA, monounsaturated fatty acids; PUFA, polyunsaturated fatty acids. Model 1 is adjusted for age, sex, BMI, triglyceride concentration, insulin dose/kg, and physical activity. Models with fatty acid have been additionally adjusted for trans-fatty acids. Model 2 is further adjusted for fibre intake. Generalized linear regression. In these substitution models, one macronutrient at the time is considered as an independent variable, while one of the macronutrients (in the parentheses) is excluded from the model. The remaining macronutrients and total energy intake remain as covariates. The obtained results represent an increase (when positive) or a decrease (when negative) in the dependent variable when the intake of the independent macronutrient is increased by $5 \%$ of total energy at the expense of the excluded macronutrient. 